\title{
Sports Science Contributes to the Development of "Integration of Sports and Education" in China
}

\author{
Dongzhe $\mathrm{Wu}^{1}$, Hui Du${ }^{2 *}$ \\ ${ }^{1}$ Sports Health and Rehabilitation Research Center, China institute of Sport Science, Beijing 100061, China \\ ${ }^{2}$ Graduate School, Capital University of Physical Education and Sports, Beijing 100091, China \\ *Correspondence Author
}

\begin{abstract}
The "integration of sports and education", as a need of the times at this stage in China, has attracted the attention of the relevant departments of the Ministry of Education and the State General Administration of Sports, as well as the widespread attention of scholars in academia. At present, the Opinions on Deepening the Integration of Sports and Education to Promote the Healthy Development of Youth has been considered and adopted by the 13th meeting of the Central Committee for Comprehensively Deepening Reform, in order to cultivate socialist builders and successors with comprehensive development of moral, intellectual, physical, social and aesthetic skills, and to propose feasible solutions to the current situation of education and sports in China based on the principle of "integrated design and integrated promotion". Opinions and implementation methods. The formal implementation of the Opinions provides a scientific basis and reference for promoting the construction of a Sports power and the healthy development of young people in China. This paper uses literature review and logical analysis to rationally explore the significance and feasibility of the development of the discipline of Sports science for the integration of sports and education in China under the background of the policies of "Sports power" and "Healthy China".
\end{abstract}

Keywords: Integration of sports and education, Sports power, Sports science.

\section{Introduction}

Since the 1960s, at the beginning of the founding of New China, China has learned from the Soviet Union's "Preparation for labour and defence of the country" sports system (the Chinese Labour and Defence System) and relied on strong policy support from the central government and the National Sports Commission to build a "National system" for competitive sports with Chinese characteristics (Meng X L and C C, 2016). The Chinese government also established an innovative model for the training of athletes: "Amateur sports schools - Provincial and municipal sports teams - National teams". Obviously, this unique and innovative model of athlete training was in line with the needs of the contemporary educational and sporting system, and it was effective in producing a large number of outstanding athletes who achieved many successes in domestic and international competitions. However, with the creation of China's socialist economic system, the development of competitive sport was faced with an unprecedented challenge - 'Reform'. Since then, the idea of "integration of sports and education" has been proposed and implemented along with the reform of the training model. The "integration of sports and education" is an important educational initiative that takes the education system as the main training body, with the ultimate goal of promoting the all-round development of human beings through competitive sports, and contributing to the national strategic plan for the cultivation of competitive sports reserves (Zhai D, 2020)." Currently, the "Sports and Education Integration" policy is being implemented. The Opinions have been adopted by the 13th meeting of the Central Committee to deepen reform, in order to cultivate a comprehensive development of moral, intellectual, physical, aesthetic and socialist builders and successors and according to the principle of "integrated design, integrated promotion" to put forward feasible opinions and implementation methods for the current situation of education and sports in China. It can be seen that the integration of sports and education provides a practical solution to the negative consequences of the long-term separation of sports and education faced by China.

Sports science, included in the undergraduate catalogue by the Ministry of Education in 1998, has made full progress in 23 years as one of the secondary disciplines of physical education in China along with the rapid development of education, sports and economic undertakings in China. As an interdisciplinary discipline, Sports Human Science mainly takes education, higher mathematics, human physiology and exercise physiology, exercise biochemistry and exercise deconstruction as its main courses, in order to train students to acquire theoretical knowledge of kinesiology, biological science and basic medicine, and to master the basic practical activities in sports science such as physical health measurement and evaluation, sports risk assessment, prevention and management of sports injuries and diseases. The main objectives are The science of sport and physical education is considered to be "A scientific process to guide the practice of sport, education and health" and is concerned with providing scientific theoretical and practical solutions to meet the sport performance, education and health needs of the population in the appropriate setting and in the context of the needs of the population (Zhang Y et al, 2020).

"The integration of sport and education has been advocated for a long time, but there are still many obstacles to overcome in the process of integration. Compared with physical education and sports training, the development of Sports science is more diversified and comprehensive, and its development direction and training objectives coincide with the "integrated design and integrated promotion" advocated by the integration of sports and education. In the new era of socialism with Chinese characteristics, the development of the 
field of sports human science, the construction of the talent team, and the optimization of the selection of reserve talents may play a pivotal role in the integration of sports and education.

\section{Analysis of Existing Problems in the Integration of Sports and Education}

\subsection{School Sports Construction}

In a 2018 study on the physical activity status of 4,269 children and adolescents aged 7 to 18 in six major administrative regions of China, it was found that the overall physical activity status of children and adolescents in China's provincial capitals was poor (Shanghai and Changsha were particularly notable), and its main manifestation was the short duration of participation in high-intensity physical activities for adolescents in this age group, with a substandard rate check as high as 70\%(Cao J, 2020). It is easy to see that the year-on-year decrease in physical activity hours and levels is due in large part to the fact that physical education class time, the fourth major subject, is still difficult to be protected effectively under the influence of national education policy reforms. The Ministry of Education, at the third session of the 13th National Committee of the Chinese People's Political Consultative Conference (CPPCC), has given a clear answer to the question: "Ensure that students get one hour of exercise every day", and strictly prohibit the squeezing out of physical education classes and physical activities on campus. According to the 2020 White Paper on Eye Health in China, the overall myopia rate among children and adolescents nationwide has reached $53.6 \%$ since $2018,81 \%$ in high schools and over $90 \%$ among university students. According to the China Population Survey, the number of children and adolescents with myopia in China has increased from 1.5 million to 1.5 million. The Report on the Status of Nutrition and Chronic Diseases among Chinese Residents shows that the overweight and obesity rate among adult residents in China has exceeded $50 \%$, the overweight and obesity rate among children and adolescents aged 6-12 is nearly 20\%, and the overweight and obesity rate among children under the age of 6 is $10 \%$. While the relevant departments propose to further improve the three-tier blindness prevention and eye health service system and strengthen the construction of professional teams of ophthalmologists at the grassroots level, should we not explore and consider more the potential factors for the high myopia rate in China in recent years, as well as the negative consequences of the obesity rate caused by the lack of physical activity among young people induced by the PE class-robbing furore.

\subsection{Construction of Sports Talents}

The General Office of the State Council has forwarded to the Ministry of Education and other departments a notice on a number of opinions on further strengthening school sports work, and the Opinions of the General Office of the State Council on Strengthening School Sports to Promote the Overall Development of Students' Physical and Mental Health have proposed that "the structural adjustment of physical education teachers should be accelerated, physical education teachers should be fully equipped according to the standards, and physical education teachers should be well equipped through multiple channels."

It can be seen that the current stage of the construction of China's physical education talent team is being innovated into a more rationalized and scientific configuration mode, from "complementary" to "reinforcement", from the scale to the stage of high quality and high standards.

To strengthen the construction of sports talent, it is proposed that proposed not only to be good in quantity but also to optimize the team structure, the pursuit of excellence in talent for school sports, competitive sports, national physical health and other areas to make due contributions, in the practice of socialist core values, with the use of sports as a bridge to promote the development of quality education.

Since 1987 to 2018, more than 30 years, China's undergraduate sports colleges and universities have only increased from 14 to 16 , an increase of $1.14 \%$, while the number of senior sports colleges and universities has increased from 2 to 21, an increase of $105 \%$, and as of 2018 the number of sports talents (senior specialist) graduated in China was 9055 with a proportion of $27.7 \%$, and the number of undergraduate graduates was 24870 , with a proportion of $73.3 \%$. The proportion of new primary and secondary school physical education teachers with undergraduate and postgraduate degrees has taken up the main position so far in 2018. However, the data shows that in 2018, only $2.6 \%$ $(16,827)$ of China's primary and secondary school physical education teachers had postgraduate degrees. In addition, the number of high school teachers with postgraduate degrees was higher than that of primary and secondary school teachers before 2013, but as of 2018, the number of high school PE teachers with postgraduate degrees was significantly lower than that of primary and middle school PE teachers (Pan J F et al,2019). Currently, the recruitment criteria for physical education teachers in primary and secondary schools and provincial and municipal sports schools in China are mostly for selecting students majoring in physical education and athletic training as reserve candidates for the physical education teacher workforce. Doubtless, in view of the training objectives of physical education and sports training majors, this group of students will be the best reserve candidates for physical education teachers, but based on the curriculum of these majors and the actual situation, in educational practice, there are often undesirable problems such as single form of education, unclear training objectives and lack of scientificity of physical education and sports training models.

\subsection{Youth Event Gradient Construction and Reform of Sports Schools}

Wang, director of the Department of Physical Health and Art Education, Ministry of Education spoke at the 2019 National Youth Campus Football League Work Conference, he emphasized that "competition is a core node to promote the 
integration of education and sports". It is clear that in order to run a four-tier competition system across primary, junior high, high school and university levels, the education and sports sectors must agree on their goals and work together to create professional campus youth sports events. However, in reality, the opposite is true, as the National Youth Games, National Youth Championships, National U Series Youth Championships and Sports School U Series Championships are almost always organised by the relevant sports departments in China, while the National University Games, National Secondary School Students' Games and National Secondary School Students' Games are organised to enrich the cultural life of schools, improve the health and fitness of young people and promote the overall development of school sports. The National University Games, National Secondary School Games and other campus sports events are mostly led and hosted by the education department. Under the far-reaching influence of the national system, the concept of separating education and sports events is still deeply rooted in people's minds, and the concept of "athletics injecting vitality into education and education adding connotation to athletics" is particularly important for the construction of a composite talent training model in the education and sports sector. The seemingly insurmountable gap between sport and education will be a major problem to be solved under the training of talents in China.

In today's society, with the increase in economicisation and the fact that the only child population has become the main pillar of the new generation since the family planning policy was introduced in 1982, a career in sports with frustrating education has not been considered a proper study and employment option, not only from the perspective of this group of people themselves but also from the perspective of their parents. This phenomenon has been influenced by the single model of training in sports schools, as more youth sports schools are subservient and dependent on the support of the local government, and the "Gold Medal First" Principle has become an important tool for most youth sports schools to increase the performance of the local government under the influence of the national system, in contrast to the proposal of "Developing sports and enhancing people's physical fitness". The slogan "sports for the people" has become a cover for the schools' reputation for hindering the development of quality education. In a study on the training model for young athletes in China, it was revealed that the number of people who are unable to complete the transition from amateur to professional athletes in China is currently around 100,000 per year. The year-on-year decline in athlete success rates is not only linked to the introduction of fewer young athletes, but in addition is directly influenced by the single goal of training athletes and the difficulty of finding employment and attending school.

\section{3 Analysis of Sports Human Science Major}

\subsection{Characteristics of the Discipline of Sports Human Science}

In 1998, after the Ministry of Education adjusted the catalogue of undergraduate majors in China's original institutions of higher education, the majors of sports health and rehabilitation and sports biological science were merged into "sports human science major", which was established with the objective of cultivating students with basic knowledge, theory and skills related to kinesiology, biological science, basic medicine and education. The pivotal aim of this major is to train students with possessing certain knowledge and skills in physical education, biological sciences, basic medicine and education, who can work in sports science research, sports training, physical education, health education and management institutions at all levels, and systematically master the theory and methods of monitoring athletes' physical functions in competitive sports, scientific fitness guidance, sports nutrition supplementation, movement analysis and evaluation, and have the basic skills and methods to engage in sports human science and sports teaching, research and laboratory operation. This course is designed to provide students with the skills and methods to teach, research and conduct experiments in sports and physical education. Unlike most foreign universities, which divide sports science into "applied sports science" and "basic sports science", both applied and basic sports science research fields are more focused on and give priority to the improvement of athletes' economic performance (Haff G G, 2010).

However, our country is different from foreign training models in the field of sports science, while the training of human resources in sports science in China should not only be dedicated to the development of competitive sports but also take up the role of education and teaching to a certain extent, play the role of advocates of sports for health in society, and provide scientific and technological support for the sustainable development of mass sports, competitive sports and national physical fitness in China under the guidance of the "Health China" policy. Under the policy, it provides scientific and technological support and services for the sustainable development of mass sports, competitive sports and national health.

\subsection{The Current Situation of the Development of Sports Science}

At present, there are more than 60 colleges and universities (including sports, teacher training, comprehensive and medical colleges and universities) offering sports human science, 46 colleges and universities with master's degree granting points and 1 scientific research institute. The number of universities with doctoral granting points has reached 23 (Niu J J et al, 2019). During the educational reform, most universities proposed that the discipline of Sports science should focus on the "Trinity" of education, training and research, which coincided with the wave of the policy of training composite talents. Although there is less research on the employment analysis of Sports science because the profession is more cross-cutting and niche, an analysis of a survey on the employment of Sports science majors at Beijing Sports University shows that most Sports science graduates tend to work mainly in Beijing and the eastern coastal region $(67.7 \%)$, the northeast and central region $(22.2 \%)$, while only $10.1 \%$ of graduates work in Only $10.1 \%$ of graduates work in 
the western region, and according to the graduate satisfaction survey, the satisfaction rate is as high as $(59.6 \%)$. With the number of graduates in China increasing year by year, the number of students choosing employment in enterprises and companies has surpassed that of institutions and state agencies, which is a reflection of the difficulties mapped out for employment in China (Wang P, 2012). Obviously, the successful start of the 2008 Olympic Games, the 2022 Winter Olympic Games, the 2021 World University Games and other large international events, the successful bid for the sports human science major brings unprecedented opportunities, and under the call of China's education reform wave, sports human science personnel training will certainly complete the perfect transition from theory to application, from application to composite.

\subsection{Sports Human Science Helps to Integrate the Development of Sports and Education}

China's Sports science research practice is not only seen in the development of competitive sports, in a study on the 11th National Sports Science Congress Sports science professional paper review, showed that the conference included 968 papers in the field of sports science, the classification of which found that in its five major topics, the system and health research topics included 304 manuscripts ranked first, the physiological basis of sports performance improvement for the research content theme was the first (106 articles), followed by the research theme of exercise and health promotion (80 articles). According to the current problems in school sport, 86 papers were published on the topic of "physical activity in adolescents" and 119 on "obesity in adolescents" (Shi H Y \& Zhao J G, 2020). It is clear that while the education and sports departments in China are still struggling with physical inactivity, obesity, myopia and other health problems caused by the barriers to integration of sports and education in school sports, there are already scholars behind the scenes who are silently helping the country to solve these seemingly intractable problems with a scientific perspective and means. And from a macro perspective, the college entrance examination selection model for Sports science talent is different from traditional physical education and athletic training majors. The college entrance examination admission scores for Sports science undergraduates are generally above the second grade line, indicating that Sports science students have a more solid cultural foundation than traditional physical education and other professional sports special students. Although students majoring in Sports science may not have the same specialization and athletic ability as students specializing in sports due to the lack of systematic training in sports in high school. However, in terms of the structure of the curriculum, students majoring in Sports science receive a richer and more varied curriculum of sports practice and more theoretical knowledge and practical skills in sports research than other non-sports majors, which are not available to sports majors. There is no doubt that, in terms of school sports, sports talent building and sports school reform, students majoring in sports human science not only build a more diversified, scientific, high-quality and high-standard talent structure for sports schools, schools and universities, but also break the previous training classes or physical education classes with a single objective and form, provide more scientific sports theoretical knowledge, optimise intra-school and inter-school guidance for high-level athletes' competitive ability. In addition, the team will work together with physical education teachers to develop a standardised ladder league system, and provide more complete competition research services with the assistance of Sports science students, so as to truly achieve a new situation of "leading training with competition and leading health with training".

\section{Conclusion}

According to more than 20 years of discipline development practice proves that, as a key application-oriented secondary discipline of physical education in China, the development of sports human science has made full progress under the rapid development of China's socialist economy. According to its disciplinary advantages, curriculum, training objectives, background and other characteristics, the development of sports human science and its scientific personnel training, can provide targeted optimization solutions for the problems faced in the "integration of sports and education" at the current stage in China, so as to provide a new way to promote the smooth implementation of the policy of integration of sports and education in China. In this way, it can provide a new pathway for the smooth implementation of the policy of integration of sports and education.

\section{Analysis and Discussion}

At present, the problems facing the integration of sports and education in China, such as policy protection, organisation and implementation, standardisation of social sports organisations and the construction of schools with traditional sports characteristics, have been relatively well elaborated and advocated in the "Opinions" on Deepening the Integration of Sports and Education and Promoting the Healthy Development of Youth issued by the General Administration of Sports and the Ministry of Education, and the introduction of local policies and implementation plans have been gradually and orderly promoted. However, the more difficult issues are still focused on school sports, sports talent team building, sports school reform and youth sports competition gradient construction and so on. Based on its disciplinary advantages, curriculum, personnel training objectives and other characteristics, the Sports science discipline provides an optimised solution to the problems faced in the integration of sports and education, such as single training, teaching and training mode and the structure of a single sports personnel team. For the development of competitive sports in the teaching and sports sector and the development of standardized leagues, it is suggested that at this stage, Sports science professionals can cross-fertilize with physical education and sports training professionals, so that each can do its part to solve existing problems in development from a more scientific perspective. Although Sports science as a product of the rapid development of China's socialist economy, there are still some shortcomings in the admissions 
standards, curriculum and other aspects, such as the discipline as a key secondary discipline of physical education should not only recruit non-athlete candidates, should properly adjust the admissions methods and admissions ratio to recruit some athletes as Sports science reserves, and in the curriculum and other aspects should cater to social. In addition to a large number of scientific research theory and practical courses, the curriculum should be optimised, and specialised sports courses should be added appropriately, so that every student majoring in Sports science can master one or more motor skills, so that theory can penetrate practice, drive sports practice through theory, and promote the creation of a new training model of scientific research teaching with practical experience. And students of traditional physical education and sports training should learn more theoretical knowledge of human body science except to physical education and other related disciplines, expand their cultural breadth and enrich their knowledge system, so as to achieve the transformation and development from high level and quality to high quality composite talents, and truly achieve the benefits of sports for the public, and in the "Health China 2030" plan. Under the "Health China 2030" planning outline, the theme of "Sports and health", the development of national physical health is led by modern sports talents in China, helping the construction of a new pattern of integration of sports and education in China.

\section{References}

[1] Meng X L, Cong C. Review of "Labor Health System" Physical Education and Exploration of School Compulsory Sports[J]. Bulletin of Sport Science \& Technology, 2016(02): 3-4+11.

[2] General Administration of Sport of China. Chinese Sports Research Since Reform and Opening up[Z]. 2009-05-05.

[3] Zhai D. Research on Some Problems of the Integrated Development of Competitive Sports and College Sports in China[D]. China University of Mining and Technology, 2020.

[4] General Administration of Sport of China \& Ministry of Education. Circular on issuing opinions on Deepening the Integration of Sports and Education to Promote the Healthy Development of Adolescents[Z]. 2020-08-31.

[5] Zhang Y. Lu J. Xu R. Bai B F., Tang Q. Research on Professional Training Objectives and Curriculum Setting of Kinesiology under the Concept of "Combination of Sports and Medicine" - Taking Nanjing Sport Institute as an Example[J]. Journal of Nanjing Sports Institute, 2020, 19(11): 65-70+2.

[6] Cao J F. Physical Activity and its Influencing Factors among Children and Adolescents of Provincial Capitals of China[Z]. East China Normal University, 2020

[7] National Health Commission. White Paper on Chinese Eye Health [Z]. 2020-06-05.

[8] Information Office of the State Council. Report on Nutrition and Chronic Diseases of Chinese Residents[R]. 2015-06-30.

[9] General Office of the State Council. Circular of The General Office of the State Council on Forwarding Opinions of the Ministry of Education and other Departments on Further Strengthening Physical Education in Schools[Z]. 2012-10-22.
[10] Pan J F. Hu X G. Han J M. Research on Structure Analysis and Allocation Optimization Strategy of PE Teachers in China in the New Era[A]. Chinese Sports Science Society. Abstracts of the 11th National Sports Science Congress[C]. Chinese Sports Science Society. 2019: 2.

[11] The Ministry of Education. Administrative Measures for Part-time Coaches of School Physical Education and Aesthetic Education[R]. 2017-10-10.

[12] Gregory Haff. Sport Science[M]. 2010.

[13] Niu J J. Wang F L. Pan F. Analysis on the Development Status of Sports Human Science Specialty in China[J]. China Higher Medical Education, 2019(02): 26-27.

[14] Wang P. Graduates' Employment Survey and Analysis on Sport Science in Beijing Sport University[D]. Beijing Sport University, 2012.

[15] Shi H Y. Zhao J G. Statistical Analysis to Human Movement Science Articles Submitted to the 11th national Conventionon Sport Science of china[J]. Journal of Shandong Normal University (Natural Science), 2020, 35(04): 492-498.

\section{Author Profile}

Dongzhe Wu, postgraduate (2020-2023), studying in China institute of Sport Science(CISS), majoring in Sports science, with the main research fields of Exercise Heart and Exercise physiology. At the same time, working as a research assistant in the China institute of Sport Science(CISS), committed to serving the development of national competitive sports and national physical health. 